\title{
Avaliação da atividade antiparasitária do alopurinol, referente ao Trypanosoma cruzi, em sistema experimental que utiliza triatomíneos infectados
}

\author{
Evaluation of antiparasitic activity of allopurinol, against \\ Trypanosoma cruzi, in experimental system using infected triatomines \\ Fábio Luís Carignani, Lúcia Maria Almeida Braz, Vicente Amato Neto \\ e Eliana Rodrigues de Souza
}

\begin{abstract}
Resumo Foi avaliada a atividade antiparasitária do alopurinol, referente ao Trypanosoma cruzi, através de procedimento que depende da utilização de triatomíneos infectados. De acordo com a metodologia usada, o fármaco não eliminou o protozoário do tubo digestivo dos insetos. Não ocorreu, portanto, obtenção de novo subsídio para melhor entendimento da posição do alopurinol no contexto do tratamento etiológico da infecção pelo T. cruzi, porquanto ela continua em foco, se bem que eivada de divergências e contradições.
\end{abstract}

Palavras-chaves: Trypanosoma cruzi. Alopurinol. Atividade no tubo digestivo de triatomíneos.

\begin{abstract}
The antiparasitic activity of allopurinol, against Trypanosoma cruzi, was evaluated by a procedure using infected triatomines. This methodology indicated that the drug was unable to eliminate the protozoa in the digestive tract of the insects. Therefore, further knowledge to improve our understanding of allopurinol in the context of the etiologic treatment of infection by T. cruzi was not acquired. Despite this finding the drug continues to be used, even though its performance appears to be full of divergences and contradictions.
\end{abstract}

Key-words: Trypanosoma cruzi. Allopurinol. Activity in the digestive tract of triatomines.

Para tratamento da infecção devida ao Trypanosoma cruzisão usados hoje o benznidazol e o nifurtimox ${ }^{3710}$. Se considerarmos a obtenção de cura sob o ponto de vista parasitológico esses fármacos propiciam bons resultados quando os pacientes estão na fase aguda da parasitose, mas os resultados são expressos em efetividade mediana e baixa quando vigentes etapas crônicas de pequena ou longa duração, respectivamente. Portanto, há necessidade de contar com medicamentos mais eficientes, sobretudo porque a imensa maioria dos acometidos por doença de Chagas é identificada quando já existe cronicidade de longa duração.
Dois compostos suscitaram esperanças: o D08970 (derivado bis-triazólico) ${ }^{13}$ e o MK-436 (nitroimidazólico) ${ }^{2}$. Contudo, investigações básicas mostraram que não podem ser administrados a seres humanos em virtude da possibilidade de promoverem expressivos efeitos adversos.

Além disso, sucedem referências às boas atividades antiparasitárias do alopurinol ${ }^{1412}$, do cetoconazol $^{5}$ e do itraconazol ${ }^{4}$, mas elas têm gerado discordâncias ${ }^{8911}$.

O alopurinol coibe reativação da infecção pelo T. cruzi em enfermos tratados por meio de transplante de coração e imunodeprimidos ${ }^{1}$.

\footnotetext{
Laboratório de Parasitologia do Instituto de Medicna Tropical de São Paulo e Laboratório de Investigação Médica - Parasitologia do Hospital das Clínicas, da Faculdade de Medicina da Universidade de São Paulo, SP, Brasil.

Endereço para correspondência: Prof. Vicente Amato Neto. Av. Dr. Enéas de Carvalho Aguiar 500, 05403-000 São Paulo, SP, Brasil.

Fax: $5511852-3622$.

e-mail: amatonet@usp.br

Recebido para publicação em 30/8/99.
} 
Também, através de modelo experimental baseado em camundongos infectados pelo T. cruzi verificou-se capacidade no sentido de inativar formas tripomastigotas ${ }^{12}$. Ainda mais, investigação levada a efeito com o intuito de avaliar a efetividade desse medicamento na terapêutica de enfermos na fase crônica da doença de Chagas, pôde ser comprovada cura parasitológica em $44 \%$ dos componentes da casuística ${ }^{4}$.

Afigura-se necessário, portanto, procurar estipular de maneira mais categórica a real utilidade do alopurinol, em virtude das contradições antes lembradas. Por isso, decidimos efetuar outra especulação acerca do assunto, utilizando metodologia idealizada no Laboratório de Parasitologia do Instituto de Medicina Tropical de São Paulo ${ }^{6}$. Segundo essa tática, triatomíneos que albergavam o T. cruzi nutriram-se em camundongos que receberam a droga submetida à apreciação.

Utilizamos 60 exemplares de Triatoma infestans, estando os insetos no quarto estádio. Quarenta encontravam-se parasitados pelo T. cruzi, tendo adquirido a protozoose ao se alimentarem em camundongos infectados pelo protozoário.

Constituímos três Grupos de animais: a) composto por 20 insetos infectados, que sugaram camundongos que haviam recebido, 30 minutos antes, por meio de sonda, $30 \mathrm{mg} / \mathrm{kg}$ de alopurinol ("Zyloric ${ }^{\circledR}$ - Glaxo Wellcome); b) com 20 insetos infectados que não sugaram camundongos; c) formado por 20 insetos não infectados, que sugaram camundongos que receberam o alopurinol, conforme referido a propósito do Grupo A.

A dose do fármaco ficou estipulada com base na empregada por Almeida ${ }^{1}$. A demarcação dos 30 minutos decorreu do conhecimento segundo o qual nesse momento sucede elevada quantidade do medicamento no sangue, em seguida à absorção.

Dez dias depois do repasto examinamos as fezes dos triatomíneos que, decorrido outro período igual, sacrificamos para analisar todo o conteúdo intestinal a fim de procurar detectar a presença do T. cruzi.

Quanto aos resultados, registramos as seguintes verificações: Grupo A) 15 triatomíneos positivos e cinco negativos; Grupo B) 15 positivos e cinco negativos; Grupo $C$ ) todos os insetos vivos.

Como decorrência do exposto, é viável deduzir que não se processou atividade antiparasitária no tubo digestivo do hemíptero, pelo menos de acordo com a metodologia escolhida. Talvez a participação de outras variáveis, por exemplo relacionadas com dose ou momento da sucção, propiciasse resultado diverso, mas de qualquer forma pareceu-nos válido registrar a ineficácia que apuramos.

Tanto em A, como em B, cinco insetos figuraram como negativos. Não é fácil explicar isso, que quiçá tenha dependido de circunstâncias ligadas aos exames ou de fases nas quais tem lugar mais efetivo encontro do parasita. Não obstante, as idênticas e elevadas positividades corroboram a dedução acerca da ineficácia do alopurinol que antes registramos.

Então, não alteramos a posição do fármaco no contexto do tratamento etiológico da infecção pelo $T$. cruzi. Ela continua em foco, se bem que eivada de divergências e contradições.

Por fim, lembramos que a técnica que usamos pode ser tida como confiável, porquanto em pesquisa anterior revelou atividade parcial do benznidazol ${ }^{6}$.

\section{REFERÊNCIAS BIBLIOGRÁFICAS}

1. Almeida DR. Transplante cardíaco no tratamento da miocardiopatia chagásica. Tese de Doutorado. Universidade Federal de São Paulo, São Paulo, SP, 1996.

2. Andrade ALSS, Zicker F, Oliveira RM, Almeida SS, Luquetti A, Travassos LR, Almeida IC, Andrade SS, Andrade JG, Martelli CMT. Randomised trial of efficacy of benznidazole in treatment of early Trypanosoma cruzi infection. The Lancet 348:1407-1413, 1996.

3. Andrade SG, Silva RC, Santiago CM, Freitas LA. Therapeutic action of MK-436 (2,5-nitroimidazole) on Trypanosoma cruzi infections in mice: a parasitological, serological, histopathological, and ultrastructural study.
Bulletin of the World Health Organization 65:625-633, 1987.

4. Apt W, Aguilera X, Arribada A, Pérez C, Miranda C, Sanchez G, Zulantay I, Cortés P, Rodriguez J, Juri D. Treatment of chronic Chagas' disease with itraconazole and allopurinol. American Journal of Tropical Medicine and Hygiene 59:133-138, 1998.

5. Brener Z, Cançado JR, Galvão LM, Luz ZM, Soule FL, Pereira ME, Santos LM, Cançado CB. An experimental and clinical assay with ketoconazole in the treatment of Chagas' disease. Memórias do Instituto Oswaldo Cruz 88:149-153, 1993. 
6. Campos R, Amato Neto V, Souza HBWT, Braz LMA. Novo processo para triagem de medicamentos na infecção experimental pelo Trypanosoma cruzi. Revista do Instituto de Medicina Tropical de São Paulo 33:325-327, 1991.

7. Fragata Filho A, Silva MAD, Boainain E. Tratamento etiológico da doença de Chagas nas fases aguda e crônica. Revista da Sociedade de Cardiologia do Estado de São Paulo 4:192-197, 1994.

8. Gianella A, Holzman A, lioshi N, Barja Z, Peredo C. Eficacia del alopurinol en la enfermedad de Chagas crónica. Resultados del estudio realizado em Santa Cruz, Bolivia. Boletin Cientifico de CENETROP 16:25-30, 1994/ 1997.

9. Lauria-Pires L, Castro CN, Emanuel A, Prata A. Ineficácia do alopurinol em pacientes na fase aguda da doença de Chagas. Revista da Sociedde Brasileira de Medicina Tropical 21:79, 1988.
10. Levi GC, Lobo IM, Kallás EG, Amato Neto V. Etiological drug treatment of human infection by Trypanosoma cruzi. Revista do Instituto de Medicina Tropical de São Paulo 38:35-38, 1996.

11. Rassi A, Luquetti AO, Rassi Junior A, Rassi GG, Silva IG, Naves HAM, Carvalho ESD. Tentativa de tratamento da infecção chagásica humana com alopurinol. Arquivos Brasileiros de Cardiologia 67 (supl 1):Res 560, 1996.

12. Souza ER, Amato Neto V, Braz, LMA, Carignani FL, Okumura M. Tratamento, por meio do alopurinol, da infecção aguda de camundongos pelo Trypanosoma cruzi. Revista Brasileira de Clínica e Terapêutica 24:5052, 1998.

13. Urbina JA, Payares G, Molina J, Sanoia C, Liendo A, Lazardi K, Piras M, Piras R, Perez N, Wincker P, Ryley J. Cure of short-and-long-term experimental Chagas' disease using D0870. Science 273:969-971, 1996. 